\title{
Enhanced apoptotic activity in allergic diseases and its relationship with eosinophil cationic protein, systemic inflammation, and severity of atopic sensitisation
}

Jong Weon Choi ${ }^{1}$, Moon Hee Lee ${ }^{2}$, Tatsuyoshi Fujii ${ }^{3}$

\author{
${ }^{1}$ Department of Laboratory Medicine, College of Medicine, Inha University, Incheon, \\ Korea (South) \\ ${ }^{2}$ Department of Internal Medicine, College of Medicine, Inha University, Incheon, \\ Korea (South) \\ ${ }^{3}$ Department of Internal Medicine, Tsukuba University Hospital Mito Clinical \\ Education and Training Centre, Mito Kyodo General Hospital, Ibaraki, Japan
}

Submitted: 17 March 2020

Accepted: 29 April 2020

Arch Med Sci

DOI: https://doi.org/10.5114/aoms.2020.95591

Copyright $\odot 2020$ Termedia \& Banach

\begin{abstract}
Introduction: The association between serum soluble apoptotic markers, eosinophil cationic protein (ECP), and inflammatory parameters in allergic diseases has seldom been studied. This study aimed to investigate apoptotic activity in allergic diseases and its relationship with ECP, systemic inflammation, and severity of atopic sensitisation.

Material and methods: A total of 125 patients with allergic diseases were investigated by measuring ECP, APO-1, tumour necrosis factor-related apoptosis-inducing ligand (TRAIL), allergen-specific immunoglobulin E (slgE), total IgE (tIgE), and high-sensitivity C-reactive protein (hsCRP) levels.

Results: ECP, APO-1, TRAIL, and hsCRP levels were significantly higher in patients with allergic diseases than in healthy individuals. Patients who tested positive for ECP had no significant differences in APO-1 and TRAIL levels compared with those who tested negative for ECP. However, among the patients who tested positive for ECP, those with elevated hsCRP concentrations had significantly higher APO- 1 and TRAIL levels than those without elevated hsCRP concentrations ( $p<0.001$, respectively). APO-1, TRAIL, and ECP levels were significantly higher in patients with inhalant allergy than in those with food allergy. APO-1 and TRAIL were significantly associated with hSCRP but not with tlgE and slgE scores.

Conclusions: Apoptotic activity is enhanced in allergic diseases and is more closely linked to concomitant systemic inflammation than to the severity of atopic sensitisation, particularly in patients with inhalant allergy.
\end{abstract}

Key words: apoptosis, inflammation, allergy, eosinophil cationic protein.

\section{Introduction}

Eosinophil cationic protein (ECP), also known as ribonuclease3 (RNase3), is a basic protein located in the eosinophil primary matrix [1]. ECP is encoded by the RNase 3 gene, released during eosinophilic degranulation, and related to asthma and airway inflammation [2]. ECP is largely responsible for damaging the bronchial mucosa, where eosinophilic infiltration occurs during asthmatic inflammation process [3]. During the progression of the inflammatory process, ECP released locally in the

\author{
Corresponding author: \\ Prof. Jong Weon Choi \\ Department of \\ Laboratory Medicine \\ College of Medicine \\ Inha University \\ Incheon, Korea (South) \\ E-mail: jwchoi@inha.ac.kr
}


inflamed mucosa is permeated to the circulation and has a systemic impact [4].

ECP is a potent cytotoxic protein that inhibits cell viability and induces cellular apoptosis [5]. However, there have been inconsistent reports regarding the cytotoxicity caused by ECP. In one study, ECP increased tumour necrosis factor- $\alpha$ (TNF- $\alpha$ ) production and triggered apoptosis via caspase activation [6], whereas in another study, lymphoma cell line treated with ECP revealed a characteristic feature of necrotic cell death [7].

APO-1 (CD95), designated as Fas molecule, is a cell surface death receptor expressed on many cells including eosinophils, which can lead to apoptosis induction when triggered by agonistic antibodies or their ligands [8]. A soluble form of APO-1 is produced via proteolytic cleavage of membrane-bound receptors or alternative splicing [9]. TNF-related apoptosis-inducing factor (TRAIL) is a death ligand, a member of the TNF/nerve growth factor superfamily. TRAIL can induce apoptosis in a broad range of human cancer cell lines. TRAIL selectively kills cancer cells without causing any harm to normal cells and is thereby a prospective candidate for cancer therapeutic strategies [10].

The role of ECP as a biomarker of airway inflammation and as a causal factor in allergic respiratory diseases has been extensively studied. However, few studies have closely examined the relationship between ECP, APO-1, and TRAIL in allergic diseases. In the present study, our hypothesis is that apoptotic activity is more closely associated with the severity of systemic inflammation than serum ECP and immunoglobulin $\mathrm{E}$ (IgE) levels in patients with allergic diseases. To test the hypothesis of this study, serum soluble apoptotic markers in allergic diseases and their relationships with ECP, allergen-specific IgE (slgE), total IgE (tlgE), and inflammatory parameters were investigated.

This study also examined which of these variables more critically contributes to apoptotic activity, particularly focused on sensitisation to food and inhalant allergens.

\section{Material and methods}

\section{Study population}

A total of 125 patients were evaluated, who were diagnosed with allergic diseases between 2017 and 2019 at Inha University Hospital. Their age ranged from 21 to 65 years (mean age: 43.5 years), with 67 patients of the male sex (53.6\%). Age- and sex-matched healthy individuals $(n=30)$, who had no evidence of allergic diseases and atopic sensitisation, were enrolled as the control group. Several variables including ECP, APO-1, TRAIL, tlgE, slgE, and high-sensitivity C-reactive protein (hsCRP) levels were measured. Body mass index (BMI) and systolic blood pressure were measured because these variables can be potential sources of bias in assessing inflammation level. The patients had the following diseases: acute bronchial asthma $(n=61)$, food allergy $(n=29)$, allergic rhinitis $(n=23)$, atopic dermatitis $(n=7)$, allergic conjunctivitis $(n=3)$, and anaphylaxis $(n=2)$. The study population with confirmed allergy was recruited based on the following criteria: a clinical history of allergic diseases, positive slgE test results (inhalant and/or food allergens determined according to the ImmunoCAP test), and elevated serum tlgE level. The exclusion criteria were as follows: subjects with medication history including corticosteroids or histamine antagonists, acute infection with fever $\left(>37.5^{\circ} \mathrm{C}\right)$, chronic illness, and recent operation. The study protocol was approved by the institutional review board, and written informed consent was obtained from all participants. This study was conducted in accordance with the guidelines of the Helsinki Declaration.

\section{Measurement of ECP, slgE, and tIgE}

Blood samples were collected from patients during their first visit to the hospital, immediately centrifuged, and stored at $-70^{\circ} \mathrm{C}$ until analysis. All specimens were obtained before treatment. The serum ECP level was measured by performing a chemiluminescent immunometric assay using an Immulite 2000 analyser (Siemens Healthcare Diagnostics, Tarrytown, NY, USA). A medical decision level for serum ECP results was defined as $19 \mu \mathrm{g} / \mathrm{l}$ based on the manufacturer's instruction. Serum concentration of slgE was tested using a fluoroenzyme immunoassay (ImmunoCAP 100, Phadia AB, Uppsala, Sweden) for identifying two of the most common inhalant allergens (Dermatophagoides pteronyssinus and Dermatophagoides farinae) and two major food allergens (egg white and cow's milk). An slgE level of $\geq 0.35 \mathrm{kU} / \mathrm{l}$ ( $\geq$ class 1 ) was considered to be indicative of allergic sensitisation [11]. The slgE score was defined as the sum of the class (0 to 6), which was assigned to each patient according to the degree of allergic sensitisation. Serum tlgE concentrations were analysed via an immunoradiometric assay (Coat-A-Count Total IgE IRMA, Siemens Healthcare Diagnostics, Tarrytown, NY, USA).

\section{APO-1, TRAIL, and inflammatory parameters}

APO-1 and TRAIL concentrations were measured via enzyme immunoassays performed using human APO-1/FasBMS245 kits (Bender MedSystems, Vienna, Austria) and Quantikine human TRAIL/TNFSF10 kits (R\&D Systems, Minneapolis, 
MN, USA), respectively. Serum hsCRP level was analysed by performing a particle-enhanced immunonephelometry assay using a chemical analyser (Hitachi 7600; Hitachi, Tokyo, Japan). An elevated hsCRP level was defined at $>0.5 \mathrm{mg} / \mathrm{dl}$, which was based on the cut-off value of the $95 \%$ confidence interval for hsCRP levels in healthy individuals. Blood eosinophil counts and absolute neutrophil counts were estimated using an automated analyser (ADVIA 120; Siemens, Forchheim, Germany).

\section{Patient categorisation}

Patients were categorised into two groups based on ECP and SlgE: patients with a positive test result for ECP (>19 $\mu \mathrm{g} / \mathrm{l} ; n=104)$ and those with a negative test result for ECP $(\leq 19 \mu \mathrm{g} / \mathrm{l} ; n=21)$, as well as patients with inhalant allergy $(n=96)$ and those with food allergy $(n=29)$. Patients who tested positive for ECP were further stratified into two groups according to hsCRP concentration: patients with an elevated hsCRP level (>0.5 mg/dl; $n=80)$ and those without an elevated hsCRP level $(\leq 0.5 \mathrm{mg} / \mathrm{dl} ; n=24)$.

\section{Statistical analysis}

Continuous variables with normal distribution were expressed as mean \pm standard deviation, and non-normally distributed data were presented as median (interquartile range). The normality of data distribution was tested using the Shapiro-Wilk test. Categorical variables were expressed as frequencies and percentages. Continuous variables with normal distribution were analysed using Student's $t$-test. Non-normally distributed data were analysed using the Mann-Whitney $U$-test. Categorical variables were analysed using the $\chi^{2}$ test. A multivariate regression analysis for elucidating the relationship between eosinophil activation and apoptosis was conducted after adjusting for potential confounders, such as age, sex, BMI, heart rate, and systolic blood pressure. Data were analysed using SPSS software (IBM SPSS Statistics for Windows, version 19.0. Armonk, NY, USA). A $p$-value of $<0.05$ was considered to be statistically significant.

\section{Results}

\section{Clinical and laboratory characteristics of subjects}

ECP, tlgE, and hsCRP levels were significantly higher in patients with allergic diseases than in the control subjects. Serum APO-1 and TRAIL concentrations in patients with allergic diseases were $420.8 \mathrm{pg} / \mathrm{ml}$ and $85.7 \mathrm{pg} / \mathrm{ml}$, respectively, which were significantly higher than those in healthy individuals (217.3 pg/ml and $42.9 \mathrm{pg} / \mathrm{ml}$, respectively, $p<0.001)$. Of the 125 patients, 104 (83.2\%) had an elevated ECP level and 91 (72.8\%) had an elevated hsCRP concentration (Table I).

Table I. Clinical and laboratory characteristics of the study population

\begin{tabular}{|c|c|c|c|}
\hline Parameter & Patients $(n=125)$ & Healthy controls $(n=30)$ & $P$-value \\
\hline \multicolumn{4}{|l|}{ Anthropometric parameters: } \\
\hline Age [year] & $43.5 \pm 10.8$ & $42.6 \pm 11.2$ & 0.671 \\
\hline Sex, male, $n(\%)$ & $67(53.6)$ & $15(50.0)$ & 0.724 \\
\hline Body mass index $\left[\mathrm{kg} / \mathrm{m}^{2}\right]$ & $22.4 \pm 3.1$ & $22.8 \pm 2.6$ & 0.415 \\
\hline Systolic blood pressure [mm Hg] & $128.3 \pm 32.5$ & $124.7 \pm 26.2$ & 0.538 \\
\hline Heart rate $[/ \mathrm{min}]$ & $76 \pm 15$ & $74 \pm 13$ & 0.216 \\
\hline \multicolumn{4}{|l|}{ Allergy-related parameters: } \\
\hline $\mathrm{ECP}[\mu \mathrm{g} / \mathrm{l}]$ & $49.6(8.7-91.9)$ & $9.1(1.7-18.6)$ & $<0.001$ \\
\hline Total IgE [IU/ml] & $383.9(20.1-987.4)$ & $12.6(3.1-86.9)$ & $<0.001$ \\
\hline Eosinophil $\left[\times 10^{9} / 1\right]$ & $0.37(0.15-0.62)$ & $0.11(0.06-0.27)$ & $<0.001$ \\
\hline Elevated ECP, $n(\%)$ & $104(83.2)$ & $1(3.3)$ & $<0.001$ \\
\hline \multicolumn{4}{|l|}{ Apoptotic markers [pg/ml]: } \\
\hline APO-1 & $420.8(225.3-647.2)$ & $217.3(126.8-416.5)$ & $<0.001$ \\
\hline TRAIL & $85.7(43.0-261.8)$ & $42.9(21.5-95.6)$ & $<0.001$ \\
\hline \multicolumn{4}{|l|}{ Inflammatory markers: } \\
\hline $\mathrm{HsCRP}[\mathrm{mg} / \mathrm{dl}]$ & $0.74(0.37-2.82)$ & $0.19(0.12-0.37)$ & $<0.001$ \\
\hline Neutrophil counts $\left[\times 10^{9} / I\right]$ & $5.41 \pm 3.27$ & $4.91 \pm 2.64$ & 0.184 \\
\hline Elevated hsCRP, $n(\%)$ & $91(72.8)$ & $0(0.0)$ & $<0.001$ \\
\hline
\end{tabular}

$E C P$ - eosinophil cationic protein, IgE - immunoglobulin E, TRAIL - tumour necrosis factor-related apoptosis-inducing ligand, HsCRP-highsensitivity $C$-reactive protein. 


\section{Clinical presentation of patients with allergic diseases}

Of the 125 patients with allergic diseases, 96 (76.8\%) had inhalant allergy and 29 (23.2\%) had

Table II. Clinical presentation of patients with allergic diseases

\begin{tabular}{|c|c|}
\hline Parameter & $\begin{array}{l}\text { Frequency (proportion) } \\
\text { in allergic patients } \\
(n=125)\end{array}$ \\
\hline Age [year] & $43.5 \pm 10.8$ \\
\hline Sex, male, $n(\%)$ & $67(53.6)$ \\
\hline \multicolumn{2}{|l|}{ Types of allergy, $n(\%)$ : } \\
\hline Inhalant allergy & $96(76.8)$ \\
\hline Food allergy & $29(23.2)$ \\
\hline \multicolumn{2}{|l|}{ History of allergy: } \\
\hline $\begin{array}{l}\text { Patients with allergic } \\
\text { attack, } n(\%)\end{array}$ & $67(53.6)$ \\
\hline $\begin{array}{l}\text { Frequency of attack, } \\
\text { median (range) [/year] }\end{array}$ & $2.3(1-9)$ \\
\hline $\begin{array}{l}\text { Duration of allergic } \\
\text { diseases, median (range) } \\
\text { [years] }\end{array}$ & $1.2(0.5-3.5)$ \\
\hline \multicolumn{2}{|l|}{ Clinical parameters: } \\
\hline $\begin{array}{l}\text { Overweight } \\
\left(\mathrm{BMI}>25.0 \mathrm{~kg} / \mathrm{m}^{2}\right)\end{array}$ & $46(36.8)$ \\
\hline Hypertension (n) & $21(16.8)$ \\
\hline
\end{tabular}

food allergy. Among the total patients, 67 (53.6\%) had a history of allergic attack, including shortness of breath, chest tightness, swelling of the airway, wheezing, or a sudden decrease in blood pressure. In the patients with allergic diseases, median duration of allergic diseases was 1.2 years, and the frequency of allergic attack was 2.3 times per year (Table II).

\section{Apoptotic activity in allergic diseases}

Serum tlgE and hsCRP levels were significantly higher in patients who tested positive for ECP than in those who tested negative for ECP. However, there were no significant differences in serum APO- 1 and TRAIL concentrations between the two groups. The slgE levels for inhalant allergens were significantly higher in patients who tested positive for ECP than in those who tested negative for ECP. However, slgE levels for food allergens did not differ between the groups. Of the 104 patients who tested positive for ECP, 80 (76.9\%) had an elevated hsCRP level, which was a significantly higher proportion than the $52.3 \%(11 / 21)$ of patients who tested negative for $\operatorname{ECP}(p=0.021)$ (Table III).

\section{Apoptosis in patients with systemic inflammation}

APO-1 and TRAIL concentrations in relation to serum hsCRP level in patients who tested positive

Table III. Apoptotic markers and inflammatory parameters in relation to ECP levels in patients with allergic diseases

\begin{tabular}{|c|c|c|c|}
\hline Parameter & $\begin{array}{l}\text { Positive test for ECP } \\
\qquad(n=104)\end{array}$ & $\begin{array}{l}\text { Negative test for ECP } \\
\qquad(n=21)\end{array}$ & $P$-value \\
\hline \multicolumn{4}{|l|}{ Anthropometric parameters: } \\
\hline Age [years] & $43.2 \pm 9.6$ & $41.5 \pm 10.4$ & 0.539 \\
\hline Sex, male, $n(\%)$ & $57(54.8)$ & $10(47.6)$ & 0.547 \\
\hline \multicolumn{4}{|l|}{ Allergy-related parameters: } \\
\hline $\mathrm{ECP}[\mu \mathrm{g} / \mathrm{l}]$ & $57.2(35.1-109.5)$ & $12.4(6.9-15.7)$ & $<0.001$ \\
\hline Eosinophil $\left[\times 10^{9} / 1\right]$ & $0.42(0.21-0.65)$ & $0.11(0.07-0.23)$ & $<0.001$ \\
\hline Total IgE [IU/ml] & $436.2(95.1-539.8)$ & $127.9(23.2-425.6)$ & $<0.001$ \\
\hline \multicolumn{4}{|l|}{ Specific lgE [kU/l]: } \\
\hline Egg white & $0.45(0.30-1.48)$ & $0.37(0.30-1.22)$ & 0.594 \\
\hline Cow's milk & $0.35(0.30-0.73)$ & $0.30(0.30-0.82)$ & 0.760 \\
\hline Dermatophagoides pteronyssinus & $6.49(0.30-45.20)$ & $0.30(0.30-5.45)$ & 0.013 \\
\hline Dermatophagoides farinae & $18.5(0.30-98.60)$ & $0.36(0.30-11.70)$ & 0.017 \\
\hline \multicolumn{4}{|l|}{ Apoptotic markers [pg/ml]: } \\
\hline APO-1 & $431.8(235.4-729.3)$ & $369.4(210.9-692.5)$ & 0.207 \\
\hline TRAIL & $87.2(49.5-241.6)$ & $79.3(41.8-194.2)$ & 0.384 \\
\hline \multicolumn{4}{|l|}{ Inflammatory marker: } \\
\hline $\mathrm{HsCRP}[\mathrm{mg} / \mathrm{dl}]$ & $0.79(0.39-1.65)$ & $0.56(0.19-1.24)$ & 0.008 \\
\hline Elevated hsCRP, $n$ (\%) & $80(76.9)$ & $11(52.3)$ & 0.021 \\
\hline Neutrophil count $\left[\times 10^{9} / 1\right]$ & $5.59 \pm 3.98$ & $4.55 \pm 2.56$ & 0.206 \\
\hline
\end{tabular}

ECP - eosinophil cationic protein, IgE - immunoglobulin E, TRAIL - tumour necrosis factor-related apoptosis-inducing ligand, HsCRP-highsensitivity C-reactive protein. 
for ECP are shown in Figure 1. Patients with an elevated hsCRP level exhibited significantly higher APO- 1 and TRAIL concentrations than those without an elevated hsCRP level $(469.1 \mathrm{pg} / \mathrm{ml}$ and 95.3 $\mathrm{pg} / \mathrm{ml}$ vs. $305.4 \mathrm{pg} / \mathrm{ml}$ and $61.2 \mathrm{pg} / \mathrm{ml}$, respectively, $p<0.001$ ) (Figure 1).

\section{APO-1 and TRAIL in relation to the type of allergy}

Patients with inhalant allergy exhibited significantly higher levels of ECP, APO-1, and TRAIL than those with food allergy $(54.7 \mu \mathrm{g} / \mathrm{l}$ vs. $32.8 \mu \mathrm{g} / \mathrm{l}, p<0.001 ; 453.9 \mathrm{pg} / \mathrm{ml}$ vs. $312.1 \mathrm{pg} / \mathrm{ml}$, $p=0.016 ; 91.2 \mathrm{pg} / \mathrm{ml}$ vs. $64.5 \mathrm{pg} / \mathrm{ml}, p=0.023)$. Serum hsCRP concentrations were two times higher in patients with inhalant allergy than those in patients with food allergy $(0.83 \mathrm{mg} / \mathrm{dl}$ vs. $0.41 \mathrm{mg} / \mathrm{dl}, p<0.001$ ) (Table IV).

\section{Effect of ECP and hsCRP on apoptotic activity}

The effect of ECP and hsCRP on apoptotic markers was evaluated. After excluding the patients with elevated ECP levels from the study subjects, APO- 1 and TRAIL levels still remained higher in the patients than in healthy individuals $(358.4 \mathrm{pg} / \mathrm{ml}$ and $69.5 \mathrm{pg} / \mathrm{ml}$ vs. $217.3 \mathrm{pg} / \mathrm{ml}$ and $42.9 \mathrm{pg} / \mathrm{ml}$, respectively, $p<0.05)$. However, after excluding the patients with elevated hsCRP levels from the study subjects, no significant difference was ob-

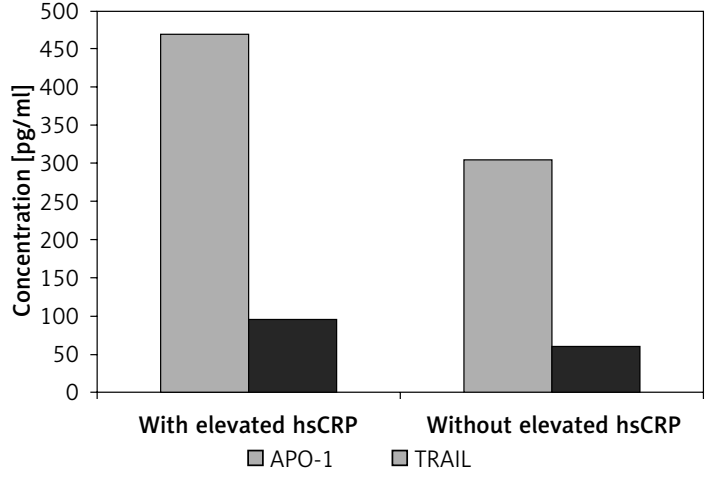

Figure 1. APO-1 and TRAIL concentrations in patients who tested positive for ECP $(n=104)$ in relation to hsCRP levels. APO-1 and TRAIL concentrations are significantly higher in subjects with elevated hsCRP levels $(n=80)$ than in subjects without elevated hsCRP levels $(n=24)(469.1 \mathrm{pg} / \mathrm{ml}$ and $95.3 \mathrm{pg} / \mathrm{ml}$ vs. $305.4 \mathrm{pg} / \mathrm{ml}$ and $61.2 \mathrm{pg} / \mathrm{ml}$, respectively, $p<0.001$ )

served in APO-1 and TRAIL levels between the two groups (Table V).

\section{Relationship between apoptotic markers, $E C P$, hsCRP, and types of allergens}

After adjusting for potential confounders, serum APO-1 and TRAIL levels were positively associated with ECP $(r=0.32$ and $r=0.29$, respectively, $p<0.001)$ and hsCRP $(r=0.34$ and $r=0.31$, respectively, $p<0.001)$. Serum ECP levels were positively correlated with hsCRP levels, tlgE, and slgE

Table IV. APO-1, TRAIL, and inflammatory parameters in relation to the type of allergy

\begin{tabular}{|c|c|c|c|}
\hline Parameter & Inhalant allergy $(n=96)$ & Food allergy $(n=29)$ & $P$-value \\
\hline \multicolumn{4}{|l|}{ Anthropometric parameters: } \\
\hline Age [years] & $43.8 \pm 10.2$ & $42.0 \pm 11.5$ & 0.612 \\
\hline Sex, male, $n(\%)$ & $51(53.1)$ & $16(55.2)$ & 0.843 \\
\hline \multicolumn{4}{|l|}{ Allergy-related parameters: } \\
\hline $\mathrm{ECP}[\mu \mathrm{g} / \mathrm{l}]$ & $54.7(24.8-93.3)$ & $32.8(19.2-67.5)$ & $<0.001$ \\
\hline Eosinophil $\left[\times 10^{9} / 1\right]$ & $0.41(0.16-0.67)$ & $0.25(0.12-0.48)$ & 0.002 \\
\hline Total IgE [IU/ml] & $451.7(121.3-876.4)$ & $162.5(48.1-401.2)$ & $<0.001$ \\
\hline \multicolumn{4}{|l|}{ Specific lgE [kU/l]: } \\
\hline Egg white & $0.3(0.3-0.3)$ & $0.64(0.3-1.46)$ & $<0.001$ \\
\hline Cow's milk & $0.3(0.3-0.3)$ & $0.51(0.3-0.99)$ & $<0.001$ \\
\hline Dermatophagoides pteronyssinus & $23.8(3.0-56.4)$ & $0.3(0.3-0.3)$ & $<0.001$ \\
\hline Dermatophagoides farinae & $52.1(11.1-105.0)$ & $0.3(0.3-0.3)$ & $<0.001$ \\
\hline \multicolumn{4}{|l|}{ Apoptotic markers [pg/ml]: } \\
\hline APO-1 & $453.9(240.8-746.1)$ & $312.1(203.4-624.5)$ & 0.016 \\
\hline TRAIL & $91.2(51.4-263.7)$ & $64.5(40.6-183.5)$ & 0.023 \\
\hline \multicolumn{4}{|l|}{ Inflammatory marker: } \\
\hline $\mathrm{HsCRP}[\mathrm{mg} / \mathrm{dl}]$ & $0.83(0.41-2.69)$ & $0.41(0.37-1.12)$ & $<0.001$ \\
\hline Neutrophil count $\left[\times 10^{9} / 1\right]$ & $5.84 \pm 3.71$ & $3.95 \pm 2.41$ & $<0.001$ \\
\hline
\end{tabular}

$E C P$ - eosinophil cationic protein, IgE - immunoglobulin E, TRAIL - tumour necrosis factor-related apoptosis-inducing ligand, HsCRP-highsensitivity C-reactive protein. 
Table V. Serum concentrations of APO-1 and TRAIL after excluding patients with elevated ECP and hsCRP levels

\begin{tabular}{|lccc|}
\hline Parameter & \multicolumn{2}{c}{ Patients with allergic diseases $(n=125)$} & Healthy individuals $(n=30)$ \\
\cline { 2 - 3 } & $\begin{array}{c}\text { After excluding subjects with } \\
\text { elevated ECP }(n=21)\end{array}$ & $\begin{array}{c}\text { After excluding subjects with } \\
\text { elevated hsCRP }(n=34)\end{array}$ & \\
\hline Age $[$ year] & $42.9 \pm 11.7$ & $43.4 \pm 10.1$ & $42.6 \pm 11.2$ \\
\hline Sex, $\mathrm{male}, n(\%)$ & $11(52.3)$ & $16(47.1)$ & $15(50.0)$ \\
\hline APO-1 $[\mathrm{pg} / \mathrm{ml}]$ & $358.4(203.5-542.7)^{*}$ & $239.4(130.4-451.8)$ & $217.3(126.8-416.5)$ \\
\hline TRAIL $[\mathrm{pg} / \mathrm{ml}]$ & $69.5(39.4-261.8)^{*}$ & $50.1(29.2-112.3)$ & $42.9(21.5-95.6)$ \\
\hline ECP $[\mu \mathrm{g} / \mathrm{l}]$ & $12.6(9.3-18.2)$ & $28.1(9.5-40.7)^{*}$ & $9.1(1.7-18.6)$ \\
\hline HsCRP $[\mathrm{mg} / \mathrm{dl}]$ & $0.57(0.35-1.61)^{*}$ & $0.15(0.23-0.42)$ & $0.19(0.12-0.37)$ \\
\hline
\end{tabular}

*Significant $(p<0.05)$, compared with healthy individuals. TRAIL - tumour necrosis factor-related apoptosis-inducing ligand, ECP eosinophil cationic protein, HSCRP - high-sensitivity C-reactive protein.

scores $(r=0.32, r=0.37$ and $r=0.26$, respectively, $p<0.001$ for all). There was no significant association between APO-1 and tlgE or slgE scores, nor between TRAIL and tlgE or slgE scores $(p>0.05$ for all). Inhalant allergens were significantly associated with ECP and hsCRP levels $(r=0.24$ and $r=0.23$, respectively, $p<0.001$ ); however, food allergens had no significant association with the corresponding parameters (Table VI).

\section{Discussion}

In the present study, the relationships between apoptotic markers, ECP, slgE, and hsCRP were assessed in patients with allergic diseases. APO-1 and TRAIL levels were significantly higher in patients with allergic diseases than in healthy subjects, demonstrating a positive relationship with ECP concentration. The results of this study revealed that apoptosis is enhanced in allergic diseases; however, apoptotic activity is elevated only when augmented ECP production is accompanied by systemic inflammation.

ECP and tlgE are reportedly increased and closely associated with each other in allergic diseases. However, conflicting results have been reported for ECP and tlgE [12]. Several studies demonstrated that there were no significant associations between ECP and serum tlgE levels in children with asthma or urticaria $[13,14]$. Additionally, serum
ECP concentrations were unexpectedly low in asthmatic patients [15]. Contrastingly, in another study, tIgE was significantly related to ECP in patients with allergic rhinitis [16]. In our study, ECP levels were positively correlated with tIgE and slgE scores. These inconsistencies may reflect the differences in both the immune response of patients and eosinophil activation in various pathologic conditions between the present and previous studies.

Bronchial asthma is characterised by chronic airway inflammation caused by immune cells. A study revealed that hsCRP level was significantly elevated in patients with asthma attacks and was related to the state of asthma exacerbation [17]. Sileem et al. [18] demonstrated that serum concentrations of hsCRP and tlgE significantly increased in asthmatic patients compared with those in healthy individuals. In our study, $72.8 \%$ of allergic patients showed an increase in hsCRP concentration. These results implied that a considerable number of allergic patients develop systemic inflammation. These findings may be attributable to an enhanced production of a potent cytotoxic ECP, which is released into systemic circulation by activated eosinophils.

Apoptosis is categorised into caspase-dependent and caspase-independent types [19, 20]. Caspase-dependent apoptosis is classified into three pathways: mitochondria-, endoplasmic re-

Table VI. Regression analysis for elucidation of the relationship between soluble apoptotic markers and ECP, hsCRP, and types of allergens in patients with allergic diseases

\begin{tabular}{|lcccc|}
\hline Parameter & \multicolumn{3}{c|}{ Multivariate regression analysis* $(n=125)$} \\
\cline { 2 - 5 } & APO-1 & TRAIL & ECP & HsCRP \\
\hline ECP $[\mu \mathrm{g} / \mathrm{l}]$ & $0.32(<0.001)$ & $0.29(<0.001)$ & Not applicable & $0.32(<0.001)$ \\
\hline HsCRP $[\mathrm{mg} / \mathrm{dl}]$ & $0.34(<0.001)$ & $0.31(<0.001)$ & $0.32(<0.001)$ & Not applicable \\
\hline Total lgE $[\mathrm{IU} / \mathrm{ml}]$ & $0.10(0.192)$ & $0.08(0.203)$ & $0.37(<0.001)$ & $0.11(0.174)$ \\
\hline Specific lgE scores & $0.12(0.117)$ & $0.07(0.214)$ & $0.26(<0.001)$ & $0.09(0.193)$ \\
\hline Inhalant allergens (scores) & $0.13(0.105)$ & $0.09(0.192)$ & $0.24(<0.001)$ & $0.23(<0.001)$ \\
\hline Food allergens (scores) & $0.08(0.202)$ & $0.05(0.314)$ & $0.06(0.219)$ & $0.04(0.425)$ \\
\hline
\end{tabular}

${ }^{*}$ Adjusted for age, sex, body mass index, heart rate, and systolic blood pressure. ECP-eosinophil cationic protein, HSCRP - high-sensitivity

$C$-reactive protein, IgE - immunoglobulin E, TRAIL - tumour necrosis factor-related apoptosis-inducing ligand. 
ticulum-associated, and death receptor-initiated pathways [21]. Several studies have reported that ECP induces apoptosis via mitochondria-independent pathway [22] and causes cytotoxicity via caspase-like activity $[23,24]$. However, the exact mechanism of ECP-induced apoptosis remains unclear. A recent study demonstrated that recombinant ECP mainly induces the necrosis of bronchial epithelial cells [25].

In this study, serum soluble apoptotic markers were evaluated in relation to serum ECP levels. There were no significant differences in APO-1 and TRAIL levels between the groups of patients with positive and negative tests for ECP. However, among the patients who tested positive for ECP, patients with elevated hsCRP levels exhibited significantly higher APO-1 and TRAIL concentrations than those without elevated hsCRP levels. Moreover, APO-1 and TRAIL were more closely associated with hsCRP than tIgE and slgE scores. These results suggest that apoptosis is more strongly induced by concomitant systemic inflammation than by atopic sensitisation or by a mere elevation in ECP level. These findings are in accordance with the results of previous studies, which demonstrated that the level of nucleosomes, a soluble parameter for apoptosis, is significantly elevated during systemic inflammation [26, 27].

Most of the allergic sensitisation initially occurs against food allergens, and the sensitisation is gradually directed against inhalant allergens [28]. Prolonged exposure to food allergens can be a major risk factor for the development of allergic airway diseases [29]. APO-1 and TRAIL levels have not yet been investigated in association with specific sensitisation to food and inhalant allergens. The current study tested the difference in apoptotic activity according to the types of allergens. APO- 1 and TRAIL levels were significantly higher in patients who tested positive for inhalant allergens than in those who tested positive for food allergens. A possible explanation for these findings is that inhalant allergens are more prone to induce systemic inflammation than ingested allergens. In fact, in the current study, serum hsCRP concentrations were two times higher in patients with inhalant allergy than in those with food allergy. Furthermore, inhalant allergens were positively associated with ECP and hsCRP levels; however, food allergens had no significant association with the corresponding parameters. These results suggest that inhalant allergens play a more important role in systemic inflammation and apoptotic regulation than food allergens.

This study examined which parameter between augmented ECP production and systemic inflammation more critically contributes to apoptotic markers in allergic diseases. When patients with elevated ECP levels were excluded from the study subjects, serum APO-1 and TRAIL concentrations were found to still be higher than the serum APO-1 and TRAIL concentrations in the control subjects. However, when patients with elevated hsCRP levels were excluded from the subjects, their serum APO-1 and TRAIL concentrations decreased to levels similar to those in the control subjects. After excluding the patients with high hsCRP levels from the study population, elevated APO-1 and TRAIL concentrations were restored to levels similar to those in healthy individuals, suggesting that concurrent systemic inflammation strongly contributes to apoptotic activity in allergic diseases.

This study has several limitations. Serum ECP levels in serial samples were not measured for assessment of the changes in ECP in association with disease progression. The slgE levels were assessed for only four specific allergens. Non-normally distributed variables may influence multivariate regression analysis, although the analysis was conducted after adjusting for potential confounders. The time frame for collecting blood samples may differ among the subject populations, particularly in regard to the exact time of an ongoing allergic attack, although blood specimens were obtained from patients during their first visit to the hospital due to severe allergic reactions. Despite these limitations, this study has considerable significance. To our knowledge, the present study shows, for the first time, the association of ECP and APO-1 and TRAIL levels, particularly in relation to food and inhalant allergens. However, further validation is warranted through larger randomized prospective studies.

In conclusion, this study demonstrates that APO-1 and TRAIL are closely linked to hsCRP and ECP but not to tlgE levels and slgE scores. Serum APO-1 and TRAIL levels were significantly higher in allergic patients with elevated hsCRP levels than in those without elevated hsCRP levels. These results suggest that enhanced apoptotic activity has crucial implication with concomitant systemic inflammation than with the intensity of atopic sensitisation, especially in patients with inhalant allergy.

\section{Acknowledgments}

This study was supported by a research grant from Inha University.

\section{Conflict of interest}

The authors declare no conflict of interest.

\section{References}

1. Boix E, Leonidas DD, Nikolovski Z, Nogues MV, Cuchillo CM, Acharya KR. Crystal structure of eosinophil cat- 
ionic protein at 2.4 A resolution. Biochemistry 1999; 38 : 16794-801.

2. Koh GC, Shek LP, Goh DY, Van Bever H, Koh DS. Eosinophil cationic protein: is it useful in asthma? A systematic review. Respir Med 2007; 101: 696-705.

3. Zedan M, Settin A, El-Chennawi F, El-Desouky T, Nasef N, Fouda A. Eosinophilic cationic protein: is it useful in assessing control of childhood asthma? East Mediterr Health J 2010; 16: 1045-9.

4. Wędrychowicz A, Tomasik P, Pieczarkowski S, Kowalska-Duplaga K, Grzenda-Adamek Z, Fyderek K. Clinical value of serum eosinophilic cationic protein assessment in children with inflammatory bowel disease. Arch Med Sci 2014; 10: 1142-6.

5. Motojima S, Frigas E, Loegering DA, Gleich GJ. Toxicity of eosinophil cationic proteins for guinea-pig tracheal epithelium in vitro. Am Rev Respir Dis 1989; 139: 801-5.

6. Trautmann A, Schmid-Grendelmeier P, Krüger K, et al. $T$ cells and eosinophils cooperate in the induction of bronchial epithelial cell apoptosis in asthma. J Allergy Clin Immunol 2002; 109: 329-37.

7. Glimelius I, Rubin J, Fischer M, et al. Effect of eosinophil cationic protein (ECP) on Hodgkin lymphoma cell lines. Exp Hematol 2011; 39: 850-8.

8. Luttmann W, Opfer A, Dauer E, et al. Differential regulation of CD95 (Fas/APO-1) expression in human blood eosinophils. Eur J Immunol 1998; 28: 2057-65.

9. Cascino I, Fiucci G, Papoff G, Ruberti G. Three functional soluble forms of the human apoptosis-inducing Fas molecule are produced by alternative splicing. J Immunol 1995; 154: 2706-13.

10. Yildiz Y, Yaylim-Eraltan I, Arikan S, Ergen HA, Küçücük S, Isbir T. Is there any correlation between TNF-related apoptosis-inducing ligand (TRAIL) genetic variants and breast cancer? Arch Med Sci 2010; 6: 932-6.

11. Ballardini N, Nilsson C, Nilsson M, Lilja G. ImmunoCAP Phadiatop Infant: a new blood test for detecting IgE sensitization in children at 2 years of age. Allergy 2006 61: 337-43.

12. Dahl R, Venge P, Olsson I. Variations of blood eosinophils and eosinophil cationic protein in serum in patients with bronchial asthma. Studies during inhalation challenge test. Allergy 1978; 33: 211-5.

13. Sugai T, Sakiyama Y, Matumoto S. Eosinophil cationic protein in peripheral blood of pediatric patients with allergic diseases. Clin Exp Allergy 1992; 22: 275-81.

14. Kim TY, Park HJ, Kim CW. Eosinophil cationic protein (ECP) level and its correlation with eosinophil number or IgE level of peripheral blood in patients with various skin diseases. J Dermatol Sci 1997; 15: 89-94.

15. Venge P, Zetterström O, Dahl R, Roxin LE, Olsson I. Low levels of eosinophil cationic proteins in patients with asthma. Lancet 1977; 2: 373-5.

16. Min HJ, Hong YH, Yang HS, Kim KS. The correlation of serum eosinophil cationic protein level with eosinophil count, and total lgE level in Korean adult allergic rhinitis patients. Asian Pac J Allergy Immunol 2016; 34: 290-4.

17. Fujita $M$, Ueki S, Ito W, et al. C-reactive protein levels in the serum of asthmatic patients. Ann Allergy Asthma Immunol 2007; 99: 48-53.

18. Sileem AE, Embarak S, Meleha MS. Serum eosinophilic cationic protein and high sensitive C-reactive protein as alternative parameters for differentiation of severity stages and monitoring control in bronchial asthma patients. Egypt J Chest Dis Tuberc 2014; 63: 765-70.
19. Riedl SJ, Shi Y. Molecular mechanisms of caspase regulation during apoptosis. Nat Rev Mol Cell Biol 2004; 5 897-907.

20. Guo H, He Y, Bu C, Peng Z. Antitumor and apoptotic effects of 5-methoxypsoralen in U87MG human glioma cells and its effect on cell cycle, autophagy and PI3K/ Akt signaling pathway. Arch Med Sci 2019; 15: 1530-8.

21. Philchenkov A. Caspases: potential targets for regulating cell death. J Cell Mol Med 2004; 8: 432-44.

22. Awad A, Yassine $H$, Barrier M, et al. Natural killer cells induce eosinophil activation and apoptosis. PLoS One 2014; 9: e94492.

23. Navarro S, Aleu J, Jiménez $M$, Boix E, Cuchillo $C M$ Nogués MV. The cytotoxicity of eosinophil cationic protein/ribonuclease 3 on eukaryotic cell lines takes place through its aggregation on the cell membrane. Cell Mol Life Sci 2008; 65: 324-37.

24. Chang KC, Lo CW, Fan TC, et al. TNF-alpha mediates eosinophil cationic protein-induced apoptosis in BEAS-2B cells. BMC Cell Biol 2010; 11: 6.

25. Bystrom J, Amin K, Bishop-Bailey D. Analysing the eosinophil cationic protein: a clue to the function of the eosinophil granulocyte. Respir Res 2011; 12: 10.

26. Holdenrieder S, Stieber P, Bodenmüller $\mathrm{H}$, et al. Nucleosomes in serum as a marker for cell death. Clin Chem Lab Med 2001; 39: 596-605.

27. Zeerleder S, Zwart B, Wuillemin WA, et al. Elevated nucleosome levels in systemic inflammation and sepsis. Crit Care Med 2003; 31: 1947-51.

28. Hattevig G, Kjellman B, Björkstén B. Appearance of IgE antibodies to ingested and inhaled allergens during the first 12 years of life in atopic and non-atopic children. Pediatr Allergy Immunol 1993; 4: 182-6.

29. Kulig M, Bergmann R, Tacke U, Wahn U, Guggenmoos-Holzmann I. Long-lasting sensitization to food during the first two years precedes allergic airway disease. Pediatr Allergy Immunol 1998; 9: 61-7. 